\title{
Kinetics and Thermodynamic Studies of the Chlorination Of Sultams Using Conductivity Measurements
}

\author{
Shireen I. Hamadamin ${ }^{1}$, Kareem Sh. Ahmed ${ }^{2}$, Hassan A. Mohammed ${ }^{3}$ \\ ${ }^{1,2,3}$ (Department of Chemistry, College of Science, Salahaddin University, Erbil, Kurdistan, Iraq)
}

\begin{abstract}
Kinetics and thermodynamic studies of chlorination of $N$-(p-substituted phenyl) $-3,5$ - dimethyl $-1,1$ dioxo-1,2-thiazine $\left(\mathrm{C}_{4} \mathrm{H}_{2}\left(\mathrm{CH}_{3}\right)_{2} \mathrm{SO}_{2} \mathrm{~N}_{6} \mathrm{H}_{4}-\mathrm{X}\right) ;\{\mathrm{X}=\mathrm{H}, \mathrm{p}$ - $\mathrm{Cl}$, and p-OCH$\}$ by using sulfuryl chloride $\left(\mathrm{SO}_{2} \mathrm{Cl}_{2}\right)$ in chloroform medium have been investigated by Isolation method the observed rate of chlorination pseudo first order for 1,2-thiazine and $\mathrm{SO}_{2} \mathrm{Cl}_{2}$ and second order in overall reaction and using conductivity method. The reaction rate constant increases with increasing temperature from $273 \mathrm{~K}$ to $318 \mathrm{~K}$. The kinetic and thermodynamic parameters $k, E_{a}, \Delta H^{\#}$ and $\Delta S^{\#}$ have been calculated. The corresponding halogenated 1,2thiazine has been identified as a product of halogenation. A suitable reaction scheme is proposed and an appropriate rate law is deduced to account for the observed kinetic and thermodynamic data.
\end{abstract}

Keywords :Sultam, Chlorination $\left(\mathrm{SO}_{2} \mathrm{Cl}_{2}\right)$, Kinetic, thermodynamic, conductivity.

\section{Introduction}

Sulfonamides have long been recognized for their wide range of biological activities ${ }^{[1]}$ and are among the most common causes of allergic reactions of drugs. Recently, much interest has been directed to their cyclic counterparts, the sultams, which also exhibit a vast variety of biological activities.

A number of substituted sultams have proven to be useful heterocycles for medical applications ${ }^{[2,3]}$. As a consequence, chemical syntheses towards sultams have continued to be an attractive topic for intense research $^{[4]}$. Sultams $\{1\}$ are inner Sulfonamides in which the $\mathrm{S}-\mathrm{N}$ bond is part of a ring, the tautomeric forms of sultams, having a sulfur-nitrogen double bond as part of a ring, are called Sultimes $\{2\}$. The chemical composition of which corresponds to the general formula ${ }^{[5]}$ :

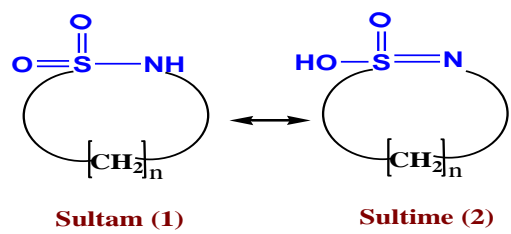

Unsaturated sultams prepared from the corresponding sultones, (Sultones are intramolecular cyclic esters of hydroxy sulfonic acids) it has surprisingly been found that unsaturated sultones may be condensed with ammonia or primary amines yielding unsaturated sultams. The reaction proceeds in accordance with the general reaction scheme ${ }^{[6]}$ :

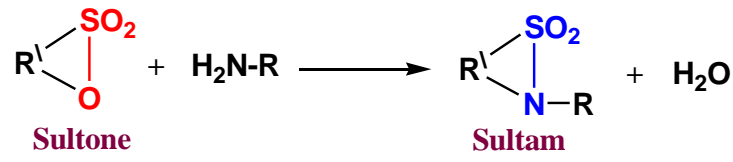

The unsaturated sultams, in accordance with the invention are highly stable and permit further reactions in the sultam ring as well as in the substituents at the sultam nitrogen atom ${ }^{[6]} .1,2$-thiazine is a type of sultams, was prepared by mixing of 4,6-dimethyl-1,2-oxathiine-2,2-dioxide $\{3\}$ with aniline $\{4\}$ or p-substituted aniline and heated for $1.5 \mathrm{hr}$., giving $\mathrm{N}$-(p-substitutedphenyl)-3,5-dimethyl-1,1-dioxo-1,2-thiazine $\{5\}^{[7]}$.

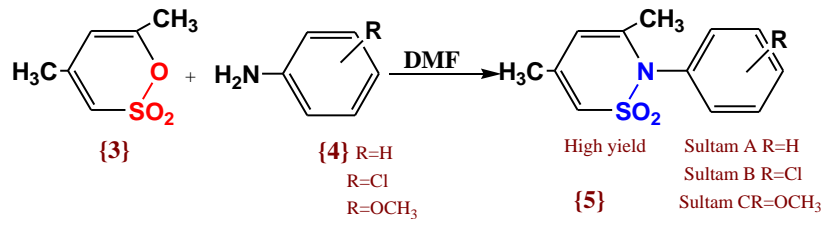

1,2-thiazine could be easily chlorinated by using sulfuryl chloride $\left(\mathrm{SO}_{2} \mathrm{Cl}_{2}\right)$ in chloroform, using different molar ratio of sulfuryl chloride, to give different chlorinated products $\{\mathbf{6 a - e}\}(\text { scheme } 1)^{[8-10]}$ : 


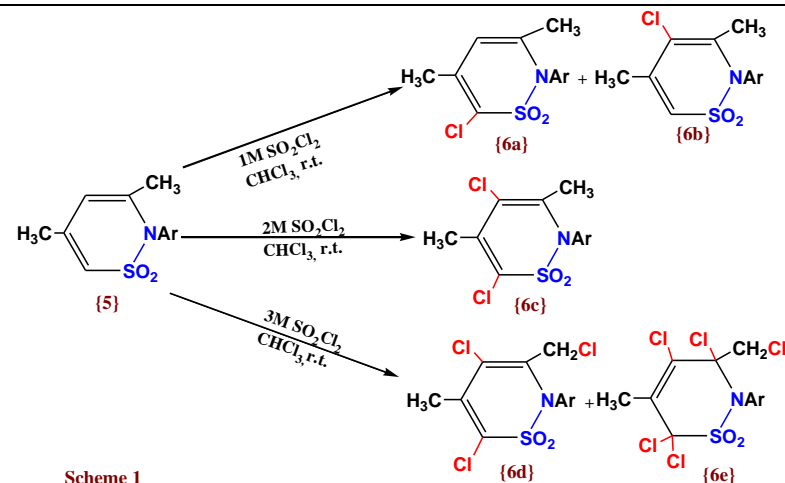

Because of our continuing interest in mild reagents for the introducing of halogens into organic molecules and because only limited kinetic and thermodynamic information is available on sultam reactions with Sulfuryl chloride, we found it is important to determine kinetic and thermodynamic parameters of the halogenation reactions of 1,2-thiazine. Electrolytic conductivity is a measure of the ability of a solution to conduct electricity. Because the ions in the solution conduct the electricity, the nature of the ions and the movement of the ions in a particular solvent determine the magnitude of the electrolytic conductivity ${ }^{[11,12]}$.

\subsection{Chemicals}

\section{Expermental}

All chemicals used were of an analytical grade reagent, and methanol (99.9\% purity) was purchased from TEDIA Company, Inc. (USA). N,N-Dimethylformamide (DMF) 99.8\% from BioSolve. Chloroform $>99.4 \%$, Sulfuryl chloride $\left(\mathrm{SO}_{2} \mathrm{Cl}_{2}\right)>97 \%$ hydrochloric acid $(\mathrm{HCl}) 97 \%$ by Fluka., Aniline $90 \%$ and sulton $98 \%$ by Sigma Aldrich Co., 4-Chloroaniline, 4-methoxyaniline by Riedel-de Haën, Franç.

\subsection{Synthesis of N-(p-substituted phenyl)-3,5-dimethyl-1,1-dioxo-1,2-thiazine}

A mixture of $0.1 \mathrm{~mole}(16 \mathrm{gm})$ sultone (3) and $0.1 \mathrm{~mole}(9.1 \mathrm{ml})$ of aniline or p-substituted aniline were dissolved in $25 \mathrm{ml} \mathrm{N}, \mathrm{N}$-dimethyl formamide (DMF), the contents reflexed for $1.5 \mathrm{hr}$, then cooled to room temperature and $10 \mathrm{ml}$ of $(0.1 \mathrm{~N}) \mathrm{HCl}$ was added to remove the excess of aniline then the precipitate collected by filtration, washed with cold water dried and recrystallized in methanol ${ }^{[13]}$. The physical properties are shown in table(1).

Table (1): Some physical properties of the compounds (sultam A, B, C).

\begin{tabular}{|c|c|c|c|c|c|}
\hline \multicolumn{2}{|l|}{ Compounds } & para- $R(p-R)$ & Molecular formula & M.wt (g/mole $)$ & Yield \% \\
\hline \multirow{3}{*}{$\begin{array}{c}\text { Sultam } \\
\text { (5) }\end{array}$} & A & $\mathrm{H}$ & $\mathrm{C}_{12} \mathrm{H}_{13} \mathrm{NO}_{2} \mathrm{~S}$ & 235.303 & 53 \\
\hline & $\mathrm{B}$ & $\mathrm{Cl}$ & $\mathrm{C}_{12} \mathrm{H}_{12} \mathrm{NO}_{2} \mathrm{SCl}$ & 269.749 & 42 \\
\hline & $\mathrm{C}$ & $\mathrm{OCH}_{3}$ & $\mathrm{C}_{13} \mathrm{H}_{15} \mathrm{NO}_{3} \mathrm{~S}$ & 265.329 & 49 \\
\hline
\end{tabular}

\section{$2.2 \quad$ Experimental techniques and apparatus}

The property was measured by Hanna conductivity meter that was readily adapted to automatic recording operation as in fig. (1) at temperatures $(273,283,293,298,303,318) \mathrm{K}$, for each temperature the conductivity was measured for a $(200 \mathrm{ml})$ water in a round bottom flask in which the acid chloride $(\mathrm{HCl})$ gas evolved as a side product of the reaction was dissolved by passing nitrogen gas flow through the reaction at different time intervals.

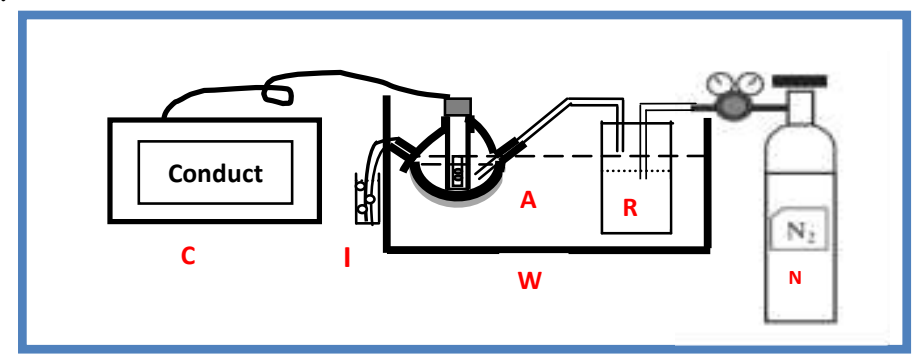

Figure(1):Illustrative schematic diagram of the electrical conductivity measurement.

2.4 Molar ratio (1:15) (SultamA : $\left.\mathrm{SO}_{2} \mathrm{Cl}_{2}\right)$

$0.235 \mathrm{~g}\left(0.001 \mathrm{~mol}, 0.1608 \mathrm{~mol} \mathrm{dm}^{-3}\right)$ of 1,2-thiazine (Sultam A) was dissolved in $5 \mathrm{ml}$ of chloroform then added in a reaction vessel (R) which is clamped in a thermostat at constant $298 \mathrm{~K}$ temperature (as illustrated in the fig. (1)) after thermal equilibrium has been reached sulfuryl chloride $\left(\mathrm{SO}_{2} \mathrm{Cl}_{2}\right) 1.215 \mathrm{ml}(0.015 \mathrm{~mol}, 2.412$ mol dm${ }^{-3}$ ) added which is also allowed in $298 \mathrm{~K}$ thermostat to come to temperature equilibrium before use. 
A pure nitrogen gas with constant speed $10 \mathrm{dm}^{3} / \mathrm{hr}$. by using gas flow meter was passed through a reaction mixture $(\mathrm{R})$ that can transfer the hydrogen chloride $(\mathrm{HCl})$ gas which is formed from the reaction, to the three necked flask (A) which contains $(200 \mathrm{ml})$ distilled water at $298 \mathrm{~K}$, and the conductivity cell was fitted with a rubber stopper and the conductivity readings from conductivity meter $(\mathrm{C})$ were recorded (the conductivity of distilled water as a blank was excluded). The other neck of the flask (A) connected by a rubber tube to the flask (I) which contains $10 \mathrm{ml}$ distilled water and indicator, the color dose not changed indicating that all $\mathrm{HCl}$ gas are trapped and dissolved in the flask (A) insuring the accuracy of the conductivity measurement.

The experiment was repeated with the same weight and volumes of reactant at each $(273,283,293,303,318) \mathrm{K}$, temperature, also for other sultams B and C.

\subsection{Molar ratio (15:1) (Sultam $\left.\mathrm{A}: \mathrm{SO}_{2} \mathrm{Cl}_{2}\right)$}

The same above experiment was repeated for (15:1) molar ratio by changing the concentrations by dissolving $3.529 \mathrm{~g}\left(0.015 \mathrm{~mol}, 2.952 \mathrm{~mol} \mathrm{dm}^{-3}\right)$ of 1,2-thiazine (Sultam A) $5 \mathrm{ml}$ of chloroform at $298 \mathrm{~K}$ and the chlorinated agent, sulfuryl chloride $\left(\mathrm{SO}_{2} \mathrm{Cl}_{2}\right) 81 \mu \mathrm{l}\left(0.001 \mathrm{~mol}, 0.196 \mathrm{~mol} \mathrm{dm}^{-3}\right)$ was added. The experiment repeated at other five temperatures $(273,283,293,303,318) \mathrm{K}$, and also performed for sultam B and C.

\subsection{Molar ratio (1:1) (Sultam A : $\mathrm{SO}_{2} \mathrm{Cl}_{2}$ )}

The same experiment was repeated for equal molar ratio changing the concentrations by dissolving $0.235 \mathrm{~g}\left(0.001 \mathrm{~mol}, 0.1968 \mathrm{~mol} \mathrm{dm}^{-3}\right)$ of 1,2-thiazine (Sultam A) $5 \mathrm{ml}$ of chloroform and the chlorinated agent, sulfuryl chloride $\left(\mathrm{SO}_{2} \mathrm{Cl}_{2}\right) 0.08 \mathrm{ml}\left(0.001 \mathrm{~mol}, 0.1968 \mathrm{~mol} \mathrm{dm}^{-3}\right)$ was added. The experiments repeated at six temperatures $(273,283,293,298,303,318) \mathrm{K}$, and also performed for sultam B and C.

\section{Results And Discussion}

3.1 The chlorination using sultam : $\mathrm{SO}_{2} \mathrm{Cl}_{2}(1: 15)$ molar ratio

The variation of conductivity of the acid chloride with time for the chlorination of the three sultams (A, B, C) at six different temperatures ranged between $(273$ to 381$) \mathrm{K}$ are shown in fig. (2) the conductivity increase with time.

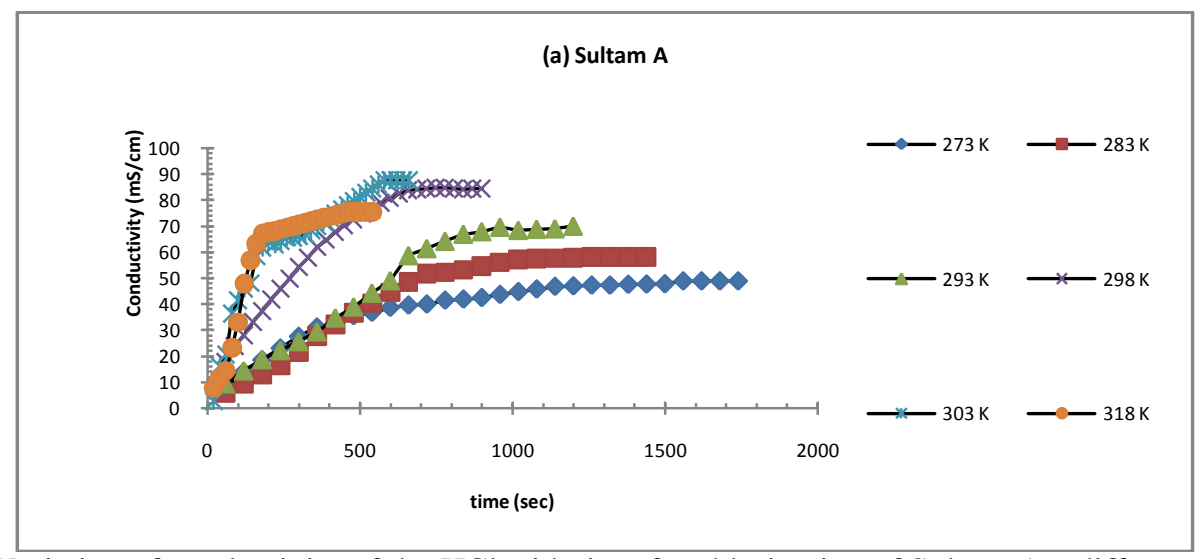

Figure (2): Variation of conductivity of the $\mathrm{HCl}$ with time for chlorination of Sultam A atdifferent temperature.

The results obtained from the kinetic data for the product of the chlorination of sultams were found to follow pseudo first-order kinetics according to the equation (1). The rate constant values (k) at different temperature were calculated for the product from the pseudo first order equation ${ }^{[14,15]}$ :

$$
\operatorname{Ln}\left(L_{\infty}-L_{t}\right)=\ln L_{\infty}-k t
$$

Where

$\mathrm{L}_{\mathrm{t}}$ : conductivity of the dissolved $\mathrm{HCl}$ gas at any time ( $\left.\mathrm{t}\right)$.

$\mathrm{L}_{\infty}$ : conductivity of the dissolved $\mathrm{HCl}$ gas at infinite time $\left(\mathrm{t}_{\infty}\right)$.

$\mathrm{t}$ : time in sec.

$\mathrm{k}$ : rate constant of reaction in $\mathrm{sec}^{-1}$.

$\left(\mathrm{L}_{\infty}-\mathrm{L}_{\mathrm{t}}\right)$ : concentration of product at any time.

The value of $k$ for each temperature was evaluated from the slope of the linear plots of $\ln \left(\mathrm{L}_{\infty}-\mathrm{L}_{\mathrm{t}}\right)$ against $(t)$, the data plots are shown in the fig. (3) and the summary of findings of $k, t_{1 / 2}$, and $R^{2}$ are given in the table (2a, $b$ and c), where $t_{1 / 2}$ is the half-life of the reaction $R^{2}$ is the correlation coefficient which is a measure of the goodnessof-fit of the regression and $0 \leq \mathrm{R}^{2} \leq 1$. 
Kinetics And Thermodynamic Studies Of The Chlorination Of Sultams Using Conductivity

\subsubsection{Determination of thermodynamic activation parameters}

The rate constants for the reaction at the six different temperatures were plotted against $1 / T$ and the activation energy $\left(E_{a}\right)$ was calculated from the slope of the Arrhenius plot (as shown in fig. (3)) which show a good straight line with the slope of $\left(-\mathrm{E}_{\mathrm{a}} / \mathrm{R}\right)$ as in the equation (2):

$$
\ln k=\ln A-E_{a} / R T
$$

From the obtained results of the activation energy $\mathrm{E}_{\mathrm{a}}$, the enthalpy of activation $\Delta \mathrm{H}^{\#}$, entropy $\Delta \mathrm{S}^{\#}$ and Gibbs free energy of activation $\Delta \mathrm{G}^{\#}$ can be obtained using equation ${ }^{[16,17]}$.

$$
\begin{aligned}
& \Delta H^{\#}=E_{a}-R T \\
& A=\frac{e K T}{h} e^{\frac{\Delta S^{\#}}{R}} \\
& \Delta S^{\#}=R\left(\operatorname{LnA}-\operatorname{Ln}\left(e k_{b} T / h\right)\right) \\
& \Delta G^{\#}=\Delta H^{\#}-T \Delta S^{\#}(6)
\end{aligned}
$$

where $\mathrm{k}_{\mathrm{b}}=1.3806 * 10^{-23} \mathrm{~J} \mathrm{~K}^{-1}, \mathrm{~h}=6.626 * 10^{-34} \mathrm{~J}$ sec.

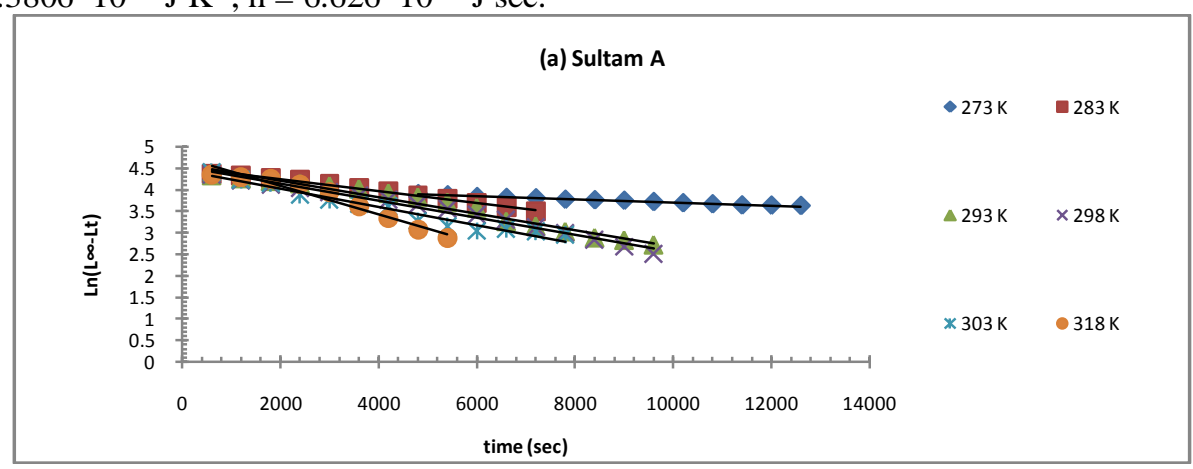

Figure (3): first order plot for the conductivity of the $\mathrm{HCl}$ of sultam A with sulfuryl chloride in chloroform using $1: 15$ molar ratio reactants.

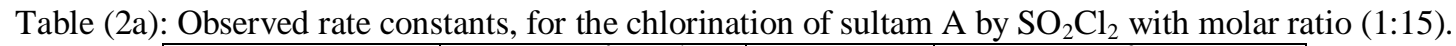

\begin{tabular}{|c|c|c|c|}
\hline Temp. $(\mathbf{K})$ & $\mathbf{k}_{\mathbf{0 b s}} \times \mathbf{1 0}^{-4}\left(\mathbf{s e c}^{-1}\right)$ & $\mathbf{t}_{\mathbf{1} / 2}(\mathbf{s e c})$ & $\mathbf{R}^{\mathbf{2}}$ \\
\hline $\mathbf{2 7 3}$ & 9 & 770 & 0.990 \\
\hline $\mathbf{2 8 3}$ & 12 & 577.5 & 0.961 \\
\hline $\mathbf{2 9 3}$ & 17 & 407.6 & 0.966 \\
\hline $\mathbf{2 9 8}$ & 20 & 346.5 & 0.970 \\
\hline $\mathbf{3 0 3}$ & 23 & 301.3 & 0.957 \\
\hline $\mathbf{3 1 8}$ & 34 & 203.8 & 0.968 \\
\hline
\end{tabular}

Table (2b): Observed rate constants, for the chlorination of sultam B by $\mathrm{SO}_{2} \mathrm{Cl}_{2}$ with molar ratio (1:15).

\begin{tabular}{|c|c|c|c|}
\hline Temp. $(\mathbf{K})$ & $\mathbf{k}_{\text {obs }} \times \mathbf{1 0}^{-\mathbf{4}}\left(\mathbf{s e c}^{-\mathbf{1}}\right)$ & $\mathbf{t}_{\mathbf{1} / \mathbf{2}} \mathbf{( \mathbf { s e c } )}$ & $\mathbf{R}^{\mathbf{2}}$ \\
\hline $\mathbf{2 7 3}$ & 0.21 & 33000 & 0.999 \\
\hline $\mathbf{2 8 3}$ & 0.57 & 12157.8 & 0.999 \\
\hline $\mathbf{2 9 3}$ & 1.4 & 4950 & 0.983 \\
\hline $\mathbf{2 9 8}$ & 2.3 & 3013 & 0.968 \\
\hline $\mathbf{3 0 3}$ & 3.5 & 1980 & 0.982 \\
\hline $\mathbf{3 1 8}$ & 11 & 630 & 0.963 \\
\hline
\end{tabular}

Table (2c): Observed rate constants, for the chlorination of sultam $\mathrm{C}$ by $\mathrm{SO}_{2} \mathrm{Cl}_{2}$ with molar ratio (1:15).

\begin{tabular}{|c|c|c|c|}
\hline Temp. $(\mathbf{K})$ & $\mathbf{k}_{\text {obs }} \times \mathbf{1 0}^{-4}\left(\mathbf{s e c}^{-1}\right)$ & $\mathbf{t}_{\mathbf{1} / \mathbf{2}} \mathbf{( \mathbf { s e c } )}$ & $\mathbf{R}^{2}$ \\
\hline $\mathbf{2 7 3}$ & 15 & 462 & 0.978 \\
\hline $\mathbf{2 8 3}$ & 20 & 346.5 & 0.994 \\
\hline $\mathbf{2 9 3}$ & 26 & 266.5385 & 0.991 \\
\hline $\mathbf{2 9 8}$ & 30 & 231 & 0.935 \\
\hline $\mathbf{3 0 3}$ & 34 & 203.8235 & 0.950 \\
\hline $\mathbf{3 1 8}$ & 48 & 144.375 & 0.973 \\
\hline
\end{tabular}




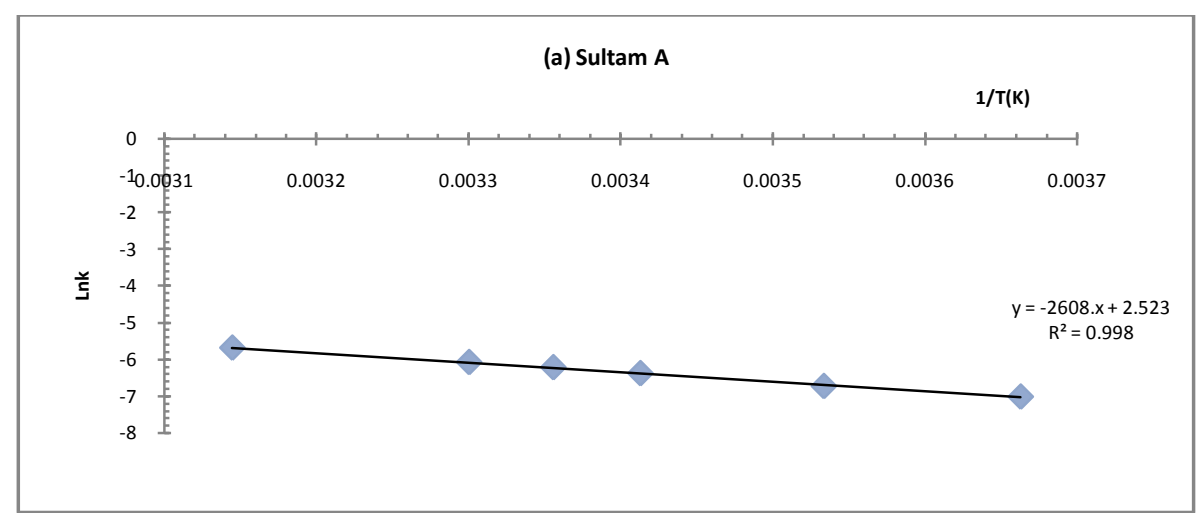

Figure (4) : Arrhenius plots for chlorination of sultam A at different temperatures using (1:15) molar ratio of sultam: $\mathrm{SO}_{2} \mathrm{Cl}_{2}$.

Table (3): Arrhenius parameters and entropies of activation for the chlorination of sultams $(\mathrm{A}, \mathrm{B}, \mathrm{C})$ using $(1: 15)$ molar ratio of sultam: $\mathrm{SO}_{2} \mathrm{Cl}_{2}$.

\begin{tabular}{|c|c|c|c|c|}
\hline $\begin{array}{c}\text { Sulta } \\
\mathrm{m}\end{array}$ & $\mathrm{E}_{\mathrm{a}}\left(\mathrm{KJ}_{\mathrm{mol}}{ }^{-1}\right)$ & $\mathrm{R}^{2}$ & $\mathrm{~A}$-factor/ & \\
\hline $\mathrm{A}$ & 21.683 & 0.998 & 12.475 & $\Delta \mathrm{S}^{\#}\left(\mathrm{~J}^{-\mathrm{mol}^{-1}} \mathrm{~K}^{-1}\right)$ at $298 \mathrm{~K}$ \\
\hline $\mathrm{B}$ & 63.765 & 0.999 & 33565187.45 & -232.237 \\
\hline $\mathrm{C}$ & 18.712 & 0.999 & 5.693 & -109.146 \\
\hline
\end{tabular}

Table (4): Thermodynamic parameters for the chlorination reaction of sultams (A, B, C) using (1:15) molar ratio ofsultam: $\mathrm{SO}_{2} \mathrm{Cl}_{2}$.

\begin{tabular}{|c|c|c|c|}
\hline Sultam & Temp. $(\mathrm{K})$ & $\Delta \mathrm{H}^{\#}\left(\mathrm{KJ}_{\mathrm{mol}}{ }^{-1}\right)$ & $\Delta \mathrm{S}^{\#}\left(\mathrm{~J} \cdot \mathrm{mol}^{-1} \mathrm{~K}^{-1}\right)$ \\
\hline \multirow{4}{*}{$\mathrm{A}$} & 273 & 19.414 & -231.508 \\
\cline { 2 - 4 } & 283 & 19.330 & -231.807 \\
\cline { 2 - 4 } & 293 & 19.247 & -232.096 \\
\cline { 2 - 4 } & 298 & 19.206 & -232.237 \\
\cline { 2 - 4 } & 303 & 19.164 & -232.375 \\
\cline { 2 - 4 } & 318 & 19.039 & -232.777 \\
\hline \multirow{4}{*}{$B$} & 273 & 61.495 & -108.418 \\
\cline { 2 - 4 } & 283 & 61.412 & -108.717 \\
\cline { 2 - 4 } & 293 & 61.328 & -109.005 \\
\cline { 2 - 4 } & 298 & 61.287 & -109.146 \\
\cline { 2 - 4 } & 303 & 61.245 & -109.284 \\
\cline { 2 - 4 } & 318 & 61.121 & -109.686 \\
\cline { 2 - 4 } & 273 & 16.442 & -238.030 \\
\cline { 2 - 4 } & 283 & 16.359 & -238.329 \\
\cline { 2 - 4 } & 293 & 16.276 & -238.618 \\
\cline { 2 - 4 } & 298 & 16.234 & -238.759 \\
\cline { 2 - 4 } & 303 & 16.193 & -238.897 \\
\cline { 2 - 4 } & 318 & 16.068 & -299 \\
\hline
\end{tabular}

\subsubsection{Interpretation of the oveall kinetic and thermodynamic results}

The results are presented in fig. (3) show the excellent fit to equation (1) proves the pseudo-first order assumption were the plots are linear. The table $(2 \mathrm{a}, \mathrm{b}, \mathrm{c})$ contains $\mathrm{k}$-values which are small indicates the reaction are slow specially the presence of $\mathrm{p}$-chlorosubstituent at benzene ring for sultam $\mathrm{B}$ due to electron withdrawing of para-ubstituted chloride, also $\mathrm{t}_{1 / 2}$ increased $\left(\mathrm{t}_{1 / 2}=630 \mathrm{sec}\right.$. at $\left.318 \mathrm{~K}\right)$ as compared with unsubstitutedsultam (A) $\left(\mathrm{t}_{1 / 2}=203.8\right.$ sec. at $\left.318 \mathrm{~K}\right)$ but the presence of $\mathrm{O}-\mathrm{CH}_{3}$ group which is electron donating group, enrich electron density of the reaction center of the formed activated complex. The rate of reaction increased, i.e. $t_{1 / 2}$ decreased $\left(\mathrm{t}_{1 / 2}=144.375 \mathrm{sec}\right.$. at $\left.318 \mathrm{~K}\right)$. 
Activation energies were calculated in fig (4) and tabulated from the table (3) which is low for sultam $\mathrm{C}\left(18.712 \mathrm{KJ} \mathrm{mol}^{-1}\right)$ as compared to sultam $\mathrm{A}\left(21.683 \mathrm{KJ} \mathrm{mol}^{-1}\right)$ and this is due to $\mathrm{p}-\mathrm{OCH}_{3}$ substituent that makes the reaction easier and faster, while the sultam $B$ has $E_{a}=63.765 \mathrm{KJ} \mathrm{mol}^{-1}$ the harder it is for the reaction to occur, these results are supports the results obtained from absorbance measurements. The enthalpy difference is positive so the reaction is endothermic it means the reaction consumes energy in its process (table 4).

The pre-exponential factor (A) has abnormal value were explained according to the transition state theory, by increase the partition function of the reactants and decrease the partition function of the transition state, according to the equation (7) which indicate the more rigid configuration with less degree of freedom for the activated complex ${ }^{[18-20]}$.

$$
A=\frac{K T}{h} * \frac{Q_{A B}^{*}}{Q_{A} Q_{B}}
$$

Also the low negative value of $\Delta \mathrm{S}^{\#}$ indicates the more rigid configuration with less degree of freedom for the activated complex than those of the reactant molecules. The presence of electron withdrawing group on the sultam lead to higher value of $\Delta \mathrm{S}^{\#}\left(-109.686 \mathrm{Jmol}^{-1} \mathrm{~K}^{-1}\right.$ at $\left.318 \mathrm{~K}\right)$ as compared with unsubstitutedsultam $\Delta \mathrm{S}^{\#}$ $\left(-232.777 \mathrm{Jmol}^{-1} \mathrm{~K}^{-1}\right.$ at $\left.318 \mathrm{~K}\right)$ causes to a less aligned and unstable transition state will the presence of electron donating group on the sultam lead to lower value of $\Delta \mathrm{S}^{\#}\left(-239.299 \mathrm{Jmol}^{-1} \mathrm{~K}^{-1}\right.$ at $\left.318 \mathrm{~K}\right)$ which obtained the more stable transition state.

\subsection{The chlorination using sultam : $\mathrm{SO}_{2} \mathrm{Cl}_{2}$ (15:1) molar ratio}

All spectra of the products that were obtained by treatment of sultam: $\mathrm{SO}_{2} \mathrm{Cl}_{2}$ as $15: 1$ molar ratios were the same as those of the starting sultam, since the small amount of chlorinated product relative to large amount of the unreacted sultam disappears, giving no detectable products.

3.3 The chlorination using sultam : $\mathrm{SO}_{2} \mathrm{Cl}_{2}(1: 1)$ molar ratio

In the chlorination of sultams; using 1:1 molar proportion of sultam and $\mathrm{SO}_{2} \mathrm{Cl}_{2}$, The conductivity of the dissolved $\mathrm{HCl}$ increase with time and this indicate that no equilibrium occurred between the product and reactants during the studied period of time.The reactions were determined as second order equation; first-order with respect to each reactant and can be described by equation $(8)^{[17-19]}$ :

$$
\frac{L_{t}}{L_{\infty}\left(L_{\infty}-L_{t}\right)}=k t
$$

Which means that the plot of $\mathrm{L}_{t} /\left(\mathrm{L}_{\infty}\left(\mathrm{L}_{\infty}-\mathrm{L}_{\mathrm{t}}\right)\right)$ with the time (t) has a slope (k) which is the second order rate constant.

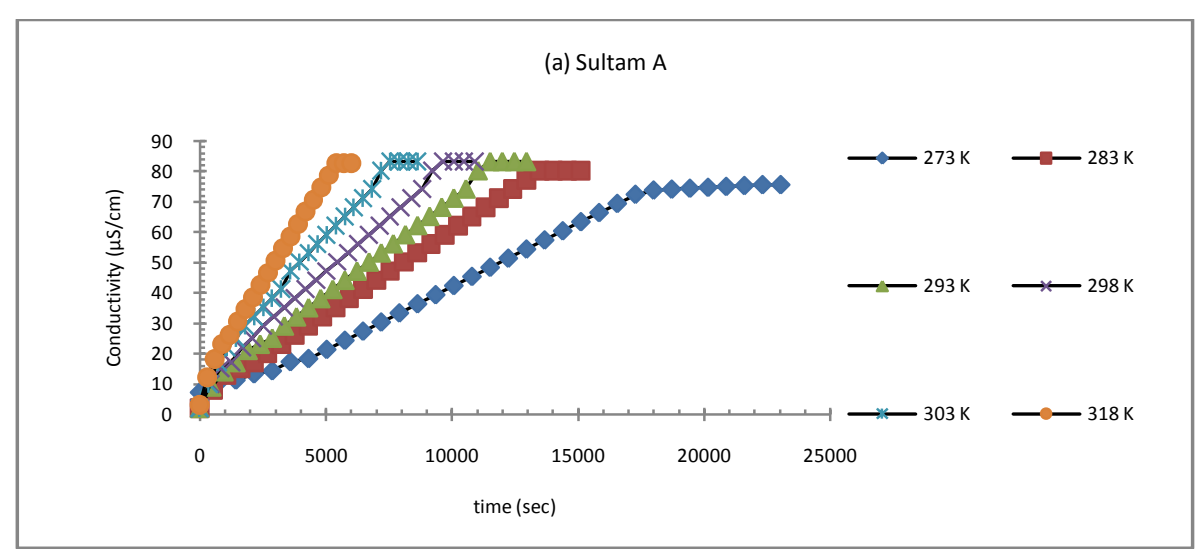

Figure (5): Variation of conductivity of $\mathrm{HCl}$ with time for chlorination of sultamsA at different temperatures using(1:1) molar ratio of sultam: $\mathrm{SO}_{2} \mathrm{Cl}_{2}$. 


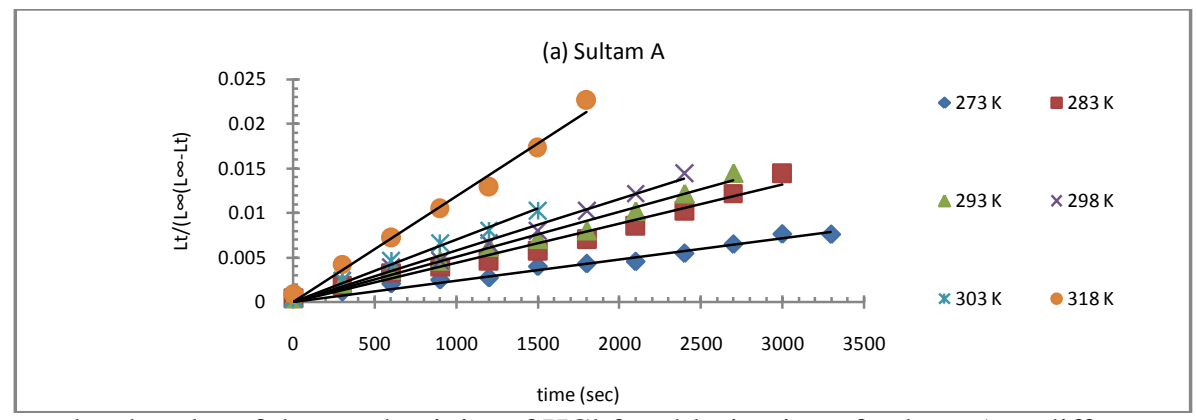

Figure (6): Second order plot of the conductivity of $\mathrm{HCl}$ for chlorination of sultam $\mathrm{A}$ at different temperatures using (1:1)molar ratio of sultam: $\mathrm{SO}_{2} \mathrm{Cl}_{2}$.

Table (5a): Observed rate constants for the chlorination of sultam A with $\mathrm{SO}_{2} \mathrm{Cl}_{2}$.

\begin{tabular}{|c|c|c|c|}
\hline Temp. (K) & $\mathrm{k}_{\mathrm{obs}} \times 10^{-4}\left(\mathrm{sec}^{-1}\right.$.L.mol. $\left.{ }^{-1}\right)$ & $t_{1 / 2}(\sec )$ & $\mathbf{R}^{2}$ \\
\hline 273 & 5.2 & 9771.732 & 0.942 \\
\hline 283 & 7.1 & 7156.762 & 0.919 \\
\hline 293 & 9.5 & 5348.738 & 0.976 \\
\hline 298 & 11 & 4619.364 & 0.923 \\
\hline 303 & 12 & 4234.417 & 0.909 \\
\hline 318 & 18 & 2822.945 & 0.939 \\
\hline
\end{tabular}

Table (5b): Observed rate constants for the chlorination of sultam B with $\mathrm{SO}_{2} \mathrm{Cl}_{2}$.

\begin{tabular}{|c|c|c|c|}
\hline Temp. $(\mathbf{K})$ & $\mathbf{k}_{\text {obs }} \times \mathbf{1 0}^{-4}\left(\mathbf{s e c}^{-1} \mathbf{.} \mathbf{.} . \mathbf{m o l}{ }^{-1}\right)$ & $\mathbf{t}_{\mathbf{1} / 2}(\mathbf{s e c})$ & $\mathbf{R}^{\mathbf{2}}$ \\
\hline $\mathbf{2 7 3}$ & 1.6 & 31758.13 & 0.915 \\
\hline $\mathbf{2 8 3}$ & 2.4 & 21172.09 & 0.996 \\
\hline $\mathbf{2 9 3}$ & 3.4 & 14945 & 0.900 \\
\hline $\mathbf{2 9 8}$ & 4 & 12703.25 & 0.946 \\
\hline $\mathbf{3 0 3}$ & 5 & 10162.6 & 0.905 \\
\hline $\mathbf{3 1 8}$ & 7 & 7259.001 & 0.966 \\
\hline
\end{tabular}

Table (5c): Observed rate constants for the chlorination of sultam C with $\mathrm{SO}_{2} \mathrm{Cl}_{2}$.

\begin{tabular}{|c|c|c|c|}
\hline Temp. $\mathbf{( K )}$ & $\mathbf{k}_{\text {obs }} \times \mathbf{1 0}^{-4}\left(\mathbf{s e c}^{-1} \mathbf{.}_{\text {..mol. }}{ }^{-1}\right)$ & $\mathbf{t}_{1 / 2}$ (sec) & $\mathbf{R}^{\mathbf{2}}$ \\
\hline $\mathbf{2 7 3}$ & 6.2 & 8195.646 & 0.907 \\
\hline $\mathbf{2 8 3}$ & 8.3 & 6122.049 & 0.983 \\
\hline $\mathbf{2 9 3}$ & 10 & 5081.301 & 0.963 \\
\hline $\mathbf{2 9 8}$ & 12 & 4234.417 & 0.983 \\
\hline $\mathbf{3 0 3}$ & 14 & 3629.501 & 0.939 \\
\hline $\mathbf{3 1 8}$ & 19 & 2674.369 & 0.897 \\
\hline
\end{tabular}

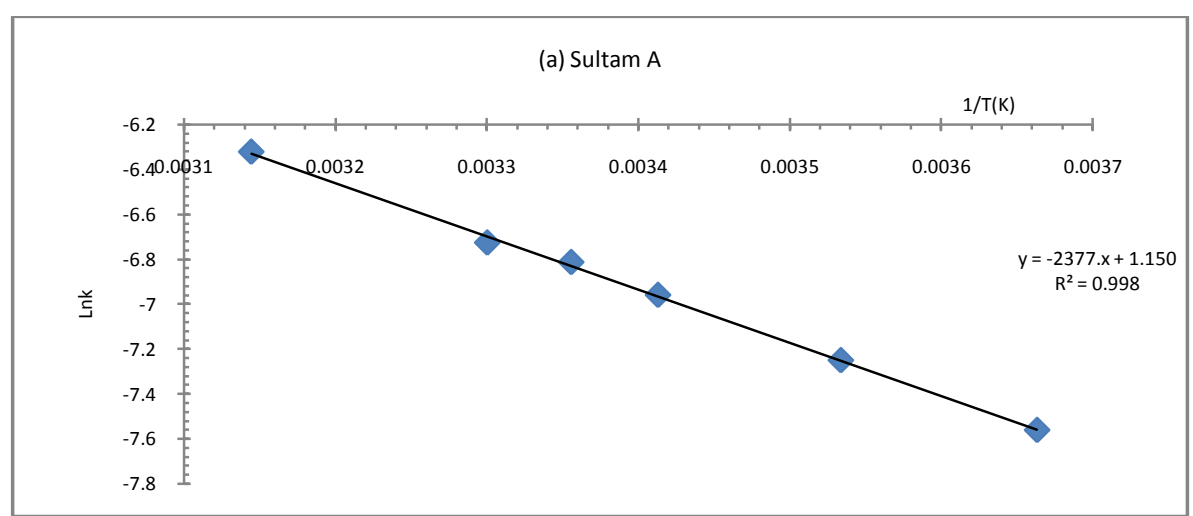

Figure (7) : Arrhenius plots for chlorination of sultam $\mathrm{A}$ at different temperatures using (1:1) molar ratio of sultam: $\mathrm{SO}_{2} \mathrm{Cl}_{2}$. 
Kinetics And Thermodynamic Studies Of The Chlorination Of Sultams Using Conductivity

Table (6): Arrhenius parameters and entropies of activation for the chlorination of sultams (A, B, C) using (1:1) molar ratio of sultam: $\mathrm{SO}_{2} \mathrm{Cl}_{2}$.

\begin{tabular}{|c|c|c|c|c|}
\hline Sultam & $\mathrm{E}_{\mathrm{a}}\left(\mathrm{KJ}_{\mathrm{mol}}{ }^{-1}\right)$ & $\mathrm{R}^{2}$ & $\begin{array}{c}\text { A-factor } \\
\left(\mathrm{sec}^{-1} . \mathrm{L} \cdot \mathrm{mol}\right)\end{array}$ & $\begin{array}{c}\Delta \mathrm{S}^{\#}\left(\mathrm{~J} \cdot \mathrm{mol}^{-1} \mathrm{~K}^{-1}\right) \\
298 \mathrm{~K}\end{array}$ \\
\hline $\mathrm{A}$ & 19.768 & 0.998 & 3.158 & -243.657 \\
\cline { 2 - 5 } & 24.065 & 0.994 & 6.554 & -237.587 \\
\hline $\mathrm{C}$ & 18.067 & 0.993 & 1.763 & -248.501 \\
\hline
\end{tabular}

Table (7): Thermodynamic parameters for the chlorination reaction of sultams (A, B, C) using (1:1) molar ratio of sultam: $\mathrm{SO}_{2} \mathrm{Cl}_{2}$.

\begin{tabular}{|c|c|c|c|}
\hline Sultam & Temp. $(\mathrm{K})$ & $\Delta \mathrm{H}^{\#}\left(\mathrm{KJ}_{\mathrm{m}} \mathrm{mol}^{-1}\right)$ & $\Delta \mathrm{S}^{\#}\left(\mathrm{~J} \cdot \mathrm{mol}^{-1} \mathrm{~K}^{-1}\right)$ \\
\hline \multirow{4}{*}{$\mathrm{A}$} & 273 & 17.498 & -242.928 \\
\cline { 2 - 4 } & 283 & 17.415 & -243.227 \\
\cline { 2 - 4 } & 293 & 17.332 & -243.516 \\
\cline { 2 - 4 } & 298 & 17.290 & -243.657 \\
\cline { 2 - 4 } & 303 & 17.249 & -243.795 \\
\hline \multirow{4}{*}{ B } & 318 & 17.124 & -244.197 \\
\cline { 2 - 4 } & 273 & 21.776 & -236.859 \\
\cline { 2 - 4 } & 283 & 21.693 & -237.158 \\
\cline { 2 - 4 } & 293 & 21.610 & -237.447 \\
\cline { 2 - 4 } & 298 & 21.569 & -237.587 \\
\hline \multirow{4}{*}{ C } & 303 & 21.527 & -237.726 \\
\cline { 2 - 4 } & 218 & 21.402 & -248.127 \\
\cline { 2 - 4 } & 273 & 15.798 & -248.072 \\
\cline { 2 - 4 } & 293 & 15.715 & -248.361 \\
\cline { 2 - 4 } & 298 & 15.631 & -248.640 \\
\cline { 2 - 4 } & 303 & 15.590 & -249.041 \\
\hline
\end{tabular}

The conductivity measurement of the dissolved acid chloride gas were investigated kinetically and thermodynamically at six different temperature for the three sultams at different time intervals, fig. (5) shows that the conductivity increases with time for the tree sultam at six different temperatures. Plotting second order equation as in fig.(6) shows the linear straight line indicated the fitness to the second order equation.

The table (5) contains the summary of findings of $\mathrm{k}, \mathrm{t}_{1 / 2}$, and $\mathrm{R}^{2}$ for the three sultams, the $\mathrm{k}$-values are small indicates the reaction are slow specially the presence of $\mathrm{p}$-chlorosubstituent at benzene ring for sultam $\mathrm{B}$ due to electron withdrawing of para substituted chlorine, also $t_{1 / 2}$ increased $\left(t_{1 / 2}=7259.001 \mathrm{sec}\right.$. at $\left.318 \mathrm{~K}\right)$ as compared with unsubstitutedsultam (A) $\left(\mathrm{t}_{1 / 2}=2822.945 \mathrm{sec}\right.$. at $\left.318 \mathrm{~K}\right)$ but the presence of $\mathrm{O}-\mathrm{CH}_{3}$ group which is electron donating group, enrich electron density of the reaction center of the formed activated complex. The rate of reaction increased, i.e. $\mathrm{t}_{1 / 2}$ decreased $\left(\mathrm{t}_{1 / 2}=2674.369\right.$ sec. at $\left.318 \mathrm{~K}\right)$.

Activation energies were calculated in the fig. (7) and tabulated in the table (6) which has lower value for sultam $\mathrm{C}\left(18.067 \mathrm{KJ} \mathrm{mol}^{-1}\right)$ as compared to sultam $\mathrm{A}\left(19.768 \mathrm{KJ} \mathrm{mol}^{-1}\right)$ and this is due to $\mathrm{p}-\mathrm{OCH}_{3}$ substituent that makes the reaction easier and faster, while the sultam $B$ has $E_{a}=24.065 \mathrm{KJ} \mathrm{mol}^{-1}$ the harder it is for the reaction to occur. The enthalpy difference is positive so the reaction is endothermic it means the reaction consumes energy in its process (table (7)).

The pre-exponential factor (A) has abnormal value were explained, according to the equation (7) which indicate the more rigid configuration with less degree of freedom for the activated complex. Also the low negative value of $\Delta \mathrm{S}^{\#}$ indicates the more rigid configuration with less degree of freedom for the activated complex than those of the reactant molecules. The presence of electron withdrawing group on the sultam (B) lead to higher value of $\Delta \mathrm{S}^{\#}\left(-238.127 \mathrm{Jmol}^{-1} \mathrm{~K}^{-1}\right.$ at $\left.318 \mathrm{~K}\right)$ as compared with unsubstitutedsultam (A) $\Delta \mathrm{S}^{\#}$ ($244.197 \mathrm{Jmol}^{-1} \mathrm{~K}^{-1}$ at $318 \mathrm{~K}$ ) causes to a less aligned and unstable transition state will the presence of electron donating group on the sultam lead to lower value of $\Delta \mathrm{S}^{\#}\left(-249.041 \mathrm{Jmol}^{-1} \mathrm{~K}^{-1}\right.$ at $\left.318 \mathrm{~K}\right)$ which obtained the more stable transition state. 


\section{Conclusion}

The proposed experimental techniques that have been used in kinetics and thermodynamic studies are quite simple and free from rigid experimental conditions and are characterized by wide linear dynamic ranges and high sensitivity. The importance of the present investigation is to demonstrate the possibility of using a modern conductivity method to investigate these reaction kinetics.

\section{Acknowledgements}

My deepest appreciation and gratitude to the higher education council, Salahaddin university-Erbil.

\section{References}

[1] C. Hansch, and P.G. Sammes, “Comprehensive Medicinal Chemistry" Pergamon press, Oxford, (1990).

[2] P. R. Hanson, D. A. Probst, R. E. Robinson, and M. Yau, Tetrahedron let. 40, 4761, (1999).

[3] P.J. Seyden, "Chiral Auxiliaries and Ligands in Asymmetric synthesis", Wiley, New York, (1995).

[4] R.C. Brown, J.L. Castro, and J-D Moriggi, Tetrahedron Let. 41, 3681, (2000).

[5] A. Jenkins, IUPAC compendium of chemical Terminology, $2^{\text {nd }}$ Ed. 67, 1370, (1995).

[6] H. Burckhardt, T. Bonner, Bonu, Germany, U.S. Pattent. No. 2,917,512, Dec.15, (1959)

[7] F. Hans, D. Beeck, and H. Tummes, Duisburg-Meiderich, Germany, U.S. pattent. No. 2,866,786, Dec. 30 (1958).

[8] Fanghenel E., Mohammed H., Richter A.M. and Radeglia R. Journal of Practical Chemestry, 326, 545, (1984).

[9] E. Earl Royals “Advanced organic chemistry” (prentice Hall United States America (1961).

[10] A.E. Shchekotikhin, Y.N. Luzikov, Y.B. Sinkevich, V.N. Buyanov, and M.N. Preobrazhenskaya, chemistry of Heterocyclic compounds, 44,10, 1245-1249 (2008).

[11] R.W. Missen, Ch. A. Mims, and B. A. Saville; "Introduction to chemical reaction engineering and kinetics", (1998),

[12] Ch. G. Hill, “An introduction to chemical engineering kinetics and reactor design" John Wiley and Sons New York, (1977).

[13] R.R. Braim, synthsis of some derevatives of the Brominated 1,2-thiazines using ultrasound technique, "M.Sc. Thesis", Salahaddin University, College of Science Chemistry Department, 1998).

[14] A.P. Uthman, P.J. Demlein, T.D. Allston, M.C. Withiam, M.J. McClements, and G.A. Takacs, J. Phys. Chem., 82, 2252, (1978).

[15] A. Semnani, H. R. Pouretedal, and M. H. Keshavarz Bull. Korean Chemical Society, 6,27, (2006).

[16] G.M. Barrow. "Physical chemistry" (McGrow Hill Inc), $4^{\text {th }}$ Ed., (1979).

[17] B.G. Gowenlock, Quart. Rev., 140, 133 (1960).

[18] P.W. Atkins "Physical chemistry", Oxford University Press, USA $5^{\text {th }}$ Ed., (1995).

[19] K.J. Laidler "Pure \& Applied Chemistry", 1, 68, 149-192 (1996).

[20] S. Alberty, J. Robert and A. Robert Physical chemistry (JohnWiley and sons, Inc. New york, $3^{\text {rd }}$ edition (2001) 